\title{
A MULTI-LEVEL RESEARCHER DEVELOPMENT FRAMEWORK TO ADDRESS CONTRASTING VIEWS OF STUDENT RESEARCH CHALLENGES
}

\author{
R. Albertyn* \\ Department Curriculum Studies \\ e-mail: rma@sun.as.za

\section{S. van Coller-Peter*} \\ e-mail: Salome.vanColler-Peter@usb.ac.za
}

\author{
J. Morrison* \\ e-mail: John.Morrison@usb.ac.za \\ *Stellenbosch University Business School \\ Stellenbosch, South Africa
}

\section{ABSTRACT}

Students often battle to complete the research component of postgraduate studies. This challenge may be due to postgraduate students having a primary interest in theoretical and practical knowledge rather than research in the era of credential inflation. Research leaders may embark on researcher development initiatives but unless both parties in the postgraduate supervision relationship are considered, these interventions may not achieve their aim. Student research challenges were explored from both student and supervisor perspectives using an Interactive Qualitative Analysis research design. Through conducting four focus groups and 14 individual interviews, issues emerged related to educational input, support and identity development. Findings revealed contrasting student and supervisor views on research challenges. Identification of both perspectives of research challenges led to the formulation of a framework of strategies for multi-level researcher development. These strategies could guide researcher development activities and contribute to ensuring accountability, enhancing quality, ensuring timely completion of postgraduate studies.

Keywords: researcher development, postgraduate supervision, research challenges, research experiences, interactive qualitative analysis.

\section{INTRODUCTION}

The era of credential inflation presents tensions in the context of postgraduate supervision and in the postgraduate relationship. The increase in numbers of students enrolling for postgraduate studies influences the quality of researcher and research produced and poses risks on multiple 
levels (Boehe 2016). There are risks to knowledge creation in the world of science, to the institution, the academic and the student.

Much has been written about the dilution of knowledge creation in the service of the economy in the neoliberal era that in turn influences quality and type of knowledge being produced (Hornsby and Osman 2014; Brodin 2015). Furthermore, institutions emphasise accountability and throughput rates resulting in a focus on technical compliance rather than quality and scholarship (Waghid 2015). Academics are under increased pressure as they are at the coalface as they navigate the massification model of education in this knowledge era where enrolments increase but faculty numbers remain static and other resources decrease (Hornsby and Osman 2014; Albertyn, Machika and Troskie-de Bruin 2016). Furthermore, students are at risk due to pressure to complete their studies that may in turn affect the originality of work produced and quality of research (Croussard 2013; Boehe 2016).

Academics are expected to fulfil their roles of teaching, leadership, knowledge exchange and research activity (Boyd and Smith 2016). The traditional one-on-one postgraduate supervision relationship entailed a primary focus on the role of leading the student through writing of the thesis/dissertation in a 'private pedagogical space' (Manathunga 2005, 17). In addition, supervisors may not be in touch with the changing needs of students which impacts on the way they approach studies and research (Albertyn, Kapp and Bitzer 2008). Moreover, the expectations on the supervisory roles have expanded in the light of the increased focus on postgraduate and doctoral pedagogy and the various outcomes (such as amongst others ontological development and research identify formation) beyond the original research (Lee and Green 2009). With the increased demands, due to the increased theorizing of supervision pedagogy, it may be useful to explore how supervisors interpret their role to gain insight into realistic strategies to support students in completion of their research.

It is also important to hear the student's voice. Pata (2009) urges educators to obtain feedback on learners' learning environment and activities when designing learning especially when there may be contrasting views of research. The context of the study reported in this article is a postgraduate Master's in Management Coaching qualification. Students are mainly mature students who enrol to increase their capital currency (Engebretson et al. 2008), and mainly for theoretical and practical skills - not to attain research skills for academic careers. Beqiri, Chase, and Bishka (2010) state that mature learners in the current economy take ownership of their own learning. They seek information in line with their personal, social and environmental goals for personal identity development (Eneau 2008). Alauddin and Ashman (2014) found in their research on the study philosophy of postgraduate students, that students in business-related programmes are more motivated by expediency drivers than students in 
other disciplines. Tymon and Batistic (2016) refer to vocational utility being the focus of business students. Although the focus in this study is on business students we argue that as more students are motivated to higher level qualifications as a means to progress in the knowledge economy, it may be useful to explore research experiences of these students whose primary focus is not on the research component of postgraduate studies.

The concern over attrition rates for postgraduate students has been reported in the UK study of Christie, Munro and Fisher $(2004,619)$ where the attrition rate was 17 per cent and in the American studies where 40-50 per cent noted by Golde $(2005,669)$ and Lovitts $(2005,139)$. In South Africa more than 50 per cent of students do not complete their studies within 7 years (Cloete, Mouton and Sheppard 2015). Blum (2010) referred to the problem of the ABD (all but dissertation) phenomenon in the USA where students complete the theoretical part of their studies but do not complete the research component. We argue that it is essential to gain insight into both the student and supervisor experiences of the research component of a higher degree in the changing higher education context to identify multi-level strategies for researcher development which may contribute to increased quality of researchers and research projects and ultimately improved completion of postgraduate qualifications.

The overall aim of our study was therefore to find ways to support supervisors and students during postgraduate supervision. Three objectives were set for this study:

- To explore the student experience of research both from a student and supervisor perspective;

- To establish the relationships between the issues identified by each role-player;

- To develop a proposed multi-level support framework for researcher development.

\section{THEORETICAL PERSPECTIVES OF THE STUDY}

Researcher development refers to a process of improving skills while improving the quality of the research (Evans 2011). It is vital to explore instructional principles associated with robust learning (Walkington 2013). In exploring ways to improve quality in postgraduate supervision we explore the three perspectives of researcher development, namely research education, relational support and personal engagement.

\section{Research education}

Cognitive or intellectual development is the basis for any form of learning. Evans (2011) describes researcher development as the mental internalisation process of research-related 
knowledge, skills, and competencies. A grasp of the fundamental knowledge base is vital. As a first step, a student needs to gain relevant research knowledge and skills (Biesta 2012). Research skills are necessary in the development of any researcher at a postgraduate level, as it provides students with the ability to create knowledge in the discipline and to gain access into their scholarly community. Carlile (2004) similarly says that the basis, in the quest for innovation and novel creation of knowledge, is the transfer of knowledge and skills.

The pedagogy of research education is a debated field; some educators approach the task via transmission of knowledge in a lecture setting, while others place more emphasis on application during the learning cycle while doing research (Wagner, Garner and Kawulich 2011). It follows that designing the facilitation of the learning process has to consider several factors. The timing of teaching is one factor mentioned by Kearns, Gardiner and Marshall (2008). They argue that a spaced learning structure (shorter sessions spread out over a longer time) is important for changing attitudes and skills development. Another key factor is to create the awareness of the need for development. As noted by Evans (2011), professional development involves an element of discontent with present practice, or what Clegg, McManus, Smith and Todd (2006) call, an unsettling period. This aligns with Mezirow's 'triggering event', which acts as a stimulus for deep change and transformation (2000).

A feeling of discomfort in the learning of a new threshold concept is to be expected and may be the case when learning about research (Kiley and Wisker 2009; Meyer and Land 2005). Raiker (2010) suggests that there may be a need to build cognitive connections between the skills and application due to the liminal spaces evident when students have to apply skills learned in their research. A further factor to consider is the point stressed by Burke and Hutchins (2007) that learning interventions need to be designed to provide adequate practice and feedback. For this to happen, the research facilitator needs to have experience both in doing research and in teaching skills (Wagner et al. 2011).

One does not only have to consider the process, but also how the student is encouraged to learn. If students are dependent they tend to have problems with research after coursework Blum (2010). This dependence may be due to over focusing on outcome . Some students may also have a prior experience of learning focusing more on performativity (Barnett 2000); a focus on demonstrating assessable qualities and content knowledge rather than skills application. Perceptions of value beyond grades are important. Burke and Hutchins (2007) link the transfer and sustained application of learning to perceptions of value and utility by students. The higher the perception of value, the more likely transfer and application of skills will happen. Evans (2014) emphasises the need for transferable skills to prepare the scholar for research beyond the qualification. Transferrable skills could then be used in evidence-based practice where 
professionals explore their practice in a rigorous way have attaining their degrees, thus ensuring they gain the skills to be life-long researchers. Skill enhancement is thus foundational to research development and has use beyond the qualification. Research education therefore provides the basis for development. A sound knowledge base is vital for researcher development but for more is needed in the research process. Relational support is a further important element.

\section{Relational support}

It is not only important to train students. They need to be supported in how to express the creative thinking needed in research (Brodin 2015). For this, a personal and interpersonal dimension is necessary in research education. The adult learning process is enhanced when it moves to a participatory one, where change is fostered in the company of others (Carlile 2004; Biesta 2012). Building on a solid knowledge base about research, independent learning and engagement in a wider set of discourses should be evident and could be enhanced through dialogue in the company of others (Abrandt Dahlgren, Hult, Dahlgren, Segerstadt and Johansson 2006). Evans (2011) refers to behaviour domains in researcher development, which include both independent and interpersonal activity.

The value of interpersonal activity and support is stressed by other scholars. Hopwood (2010) refers to sociocultural theories, which assert that human development is based on social interaction in cultural practices. Dysthe, Samara and Westrheim (2006) state that gaining knowledge is both a process and a product of interaction. Ball (2009) refers to social exchange, where others that are more informed, encourage learners towards conceptual innovativeness. Understanding is developed and transformed through tensions between multiple perspectives and opinions. The use of Socratic questioning is one such technique to encourage empowerment in postgraduate supervision (Frick, Albertyn and Rutgers 2009). Feedback provides indications of what is valued in a scholarly community (Basturkmen, East and Bitchener 2014) and supportive feedback increases perception of the efficacy of training (Burke and Hutchins 2007).

The notion of communities of practice or situated learning refers to a learning ecology where reciprocal learning from each other is characterised by productive reflection for creativity and development of new knowledge (Wenger 1998; Fenge 2012; Buissink-Smith, Hart and Van der Meer 2013). The relationship is not limited to the student-supervisor relationship alone, but also relies on peer learning (Burke and Hutchins 2007; Samuel and Vithal 2011). In the study by Sinclair, Barnacle and Cuthbert (2014), they found that successful researchers acknowledge the role of others in their success. In facilitating researcher development, it may be helpful to harness generative interpersonal relationships. Edwards (2011) suggests that by engaging 
collectively with the knowledge and motives of others, a common knowledge that contributes to a common vision can be plotted, thus ensuring that there is some understanding of what matters reciprocally for all parties. Brodin (2015) refers to the relational approach where responsibility, care and respect for the individual voice is vital and provides promising conditions for constructive and creative knowledge production. Personal engagement is another dimension of researcher development.

\section{Personal engagement}

The individual and their agency can be used to help enhance change and development. Hopwood (2010) explains that people engage in activities because they can see the value of the activity. There should thus be purposeful engagement in the process. According to Hodge (2014), individual agency or personal connection is the basis of Mezirow's transformative or deep sustained learning. The importance of personal engagement is reflected in the study by Sinclair et al. (2014), who found hard work, perseverance, determination and tenacity to be attributes reported by successful researchers.

Personal feelings influence outcomes of research education as illustrated in the study by Burke and Hutchins (2007) who found that while general intelligence was important in looking at the long-term effects of training, self-efficacy, a belief in competency, is a more important factor. Sinclair et al. (2014) claim that the art of managing the self and circumstances in an enterprising manner (they use the term 'entrepreneurial subjectivity') is important in successful researcher development. Burke and Hutchins (2007) refer to the strategy of metacognition; the learners' ability to self-monitor to maximise learning and performance.

Personal engagement will be influenced by perceptions or attitudes to research (Evans 2011). She emphasises domains of change when focusing on researcher development, namely perceptual, evaluative and motivational change. Perceptual change refers to changing views of how scholars' research is seen as a key component of their work or professional identity. This notion is supported by Burke and Hutchins (2007) and by Reid and Petocz (2004), who call this intrinsic meaning where students perceive professional work (research) as essentially related to their own personal and professional position. Evaluative change refers to causing students to revalue what they consider as important about research and researching.

The third aspect, motivational change involves increasing the basis of motivation and the satisfaction students can derive from their research activity. Genuine enthusiasm for discovery and curiosity leads Sinclair et al. (2014) to suggest the importance of a 'calling'. This seems to tie in with the ontological development of researchers (Dall'Alba and Barnacle 2007). Tapping into the personal dimension and trying to instil a sense of vocation or a connection to the 
researcher's own engagement seems to be warranted.

\section{RESEARCH METHODS}

The context of this study was a master's qualification in Management Coaching. Students attend five week-long residential modules in their first year during which time they are exposed to research education that culminates in the research proposal at the end of the year. After proposal defence, students are allocated to supervisors and are expected to complete the research and graduate at the end of the second year of study. The students find it hard to complete the research in the allocated time; therefore the student perspective of the challenges they face would provide insight into appropriate support that they may need and find beneficial.

The research design, Interactive Qualitative Analysis (IQA), was employed in this study (Northcutt and McCoy 2004). IQA facilitates identification of the elements (affinities) and relationships between the elements of the system by participants (constituencies) who have direct experience of the phenomenon in a focus group setting. Data is generated in an interactive collaborative process and ultimately a visual display of the affinities and their relationships in a system of influence (Systems Influence Diagram - SID) is produced.

The first inductive phase of data collection consisted of four focus group sessions, two with supervisors (a total of 11 participants) and two with students (17 participants). Each focus group commenced with a clarification exercise using guided imagery before participants were asked to individually and silently generate key thoughts triggered by the issue statement and to write down one idea per card. The issue statement posed to both students and supervisors was: 'Tell me about the experience of students during the research component of their studies'. After production of elements was complete, the next step in the IQA focus group was the inductive and axial coding process in which participants worked collectively to group the items into affinities (inductive coding) and to label these cluster of affinities (axial coding). Individual participants then conducted theoretical coding by considering the relationships between affinities; a pairwise indication of the perceived influences of all affinities relative to each other (a pro-forma affinity relationship table (ART) was used).

Systems Influence Diagrams (SIDs) were generated for individual participants using data from the focus group. The individual SIDs were converted to group composite SIDs using the Pareto table, one for each focus group. The SIDs reflected the relationships between issues and allowed comparison between various groups; supervisor and student perceptions as well as individual comparisons. For the purposes of this article only the composite SID from one student and one supervisor focus group is presented. Full description of various SIDs have been reported elsewhere (Albertyn, Van Coller-Peter and Morrison 2016). 
During the second phase of IQA, individual semi-structured interviews with a sample of ten students and four supervisors who had attended the focus group meetings and who volunteered to participate. The affinities identified for each relevant focus group served as the interview guide. Interviews were conducted face-to-face or via skype and lasted approximately one hour. The aim of the interview was to gather rich data on affinities generated in each group and also to gain insight in identifying support for students and supervisors (final objective of the study).

Interview recordings were transcribed and after member checking, the data was coded and analysed using the IQA protocol (Northcutt and McCoy 2004). Ethical clearance was obtained from the University where the study was conducted and all participants signed informed consent forms for participation in the focus groups and interviews. Participation in both the focus group and interview was voluntary. All supervisors and students who had been registered for the past three years (completed or currently registered) were invited to attend.

\section{FINDINGS AND DISCUSSION}

Seventeen students and 11 supervisors voluntarily took part in the focus groups. Three students had completed their research and the rest (14) were still in the process of conducting the research. Ten of the seventeen students volunteered to take part in the interviews after the focus group. Two of the ten students who were interviewed had completed their studies. Four supervisors were willing to participate in the interview phase of the study.

We designed a the multi-level framework for researcher development based on analysis of findings. We report these findings by firstly describing the contrasting students and supervisors realities and secondly the development of the multi-level framework according to the three dimensions of researcher development (research education, support and personal identity). Direct quotes from interviews are referenced using the suffix 'St' for students and 'Su’ for supervisors.

\section{Contrasting student and supervisor realties}

We illustrate contrasting realities by presenting one student and one supervisor SID. The IQA research design extracted different realities from each group. A visual representation is illustrated in Figure 1 and 2 which displays individual and group perceptions of interrelationship between affinities (variables). The student SID in figure one indicates the primary driver (research educational input) and the primary outcomes (feelings) 


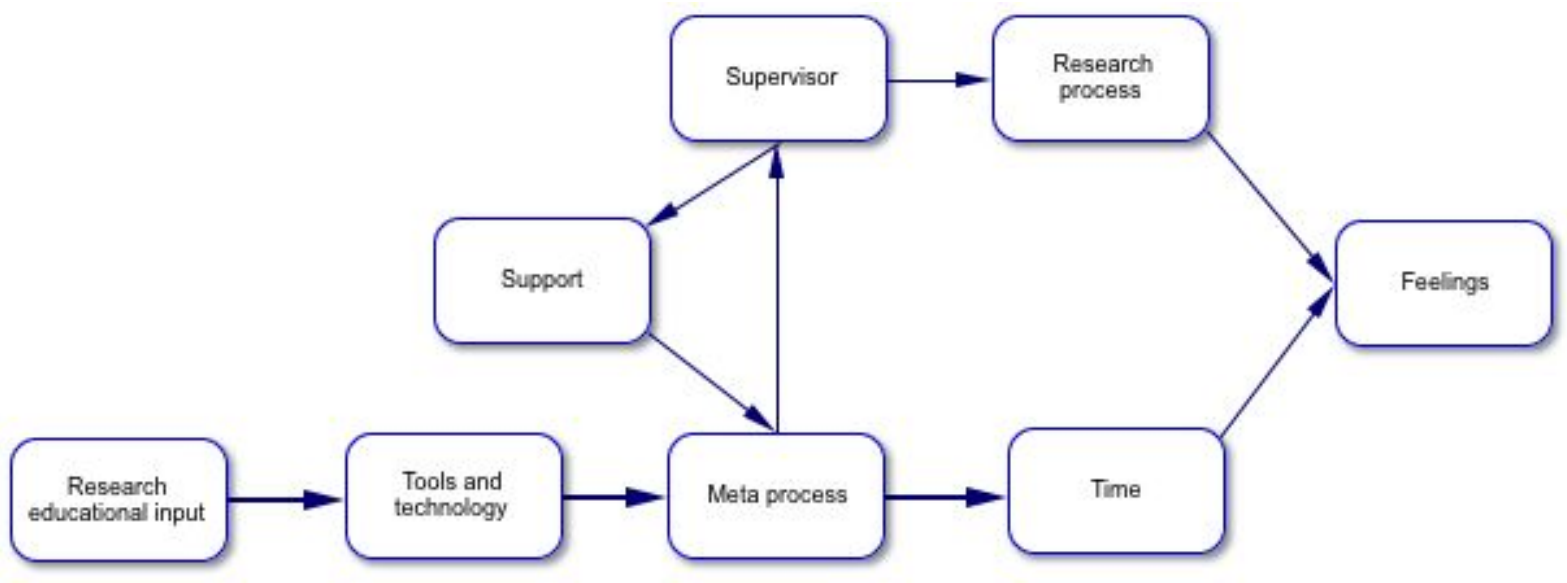

Figure 1: Systems influence diagram for students

When examining the student SID we notice that they see research educational input as the primary driver in the research process and this confirms the importance of a solid theoretical knowledge in developing research skills. Students supplement their knowledge by self-study and use of tools and technology (for example using reference managers, data analysis tools and internet sources). Meta-process in the case of this focus group included elements which they identified in the groups, such as 'balance', 'structure', 'direction', 'workflow' and 'processes'. The meta-process is a pivot that influences time and feelings. (A pivot indicates that there are an equal number of factors influencing the affinity, as that it influences other affinities.) The supervisor and support both play a role as secondary drivers and feed into the meta-process. Indirectly via the supervisor, the meta-process influences the research process and directly influences time and ultimately the feelings of the students.

The Supervisors' SID indicates a stronger focus on individuals coupled with strong emphasis on support rather than research knowledge and skill (Figure 2). This finding makes sense as these supervisors play a role mostly during the application phase of conducting the research and not during the research teaching in class (during the first year of study).

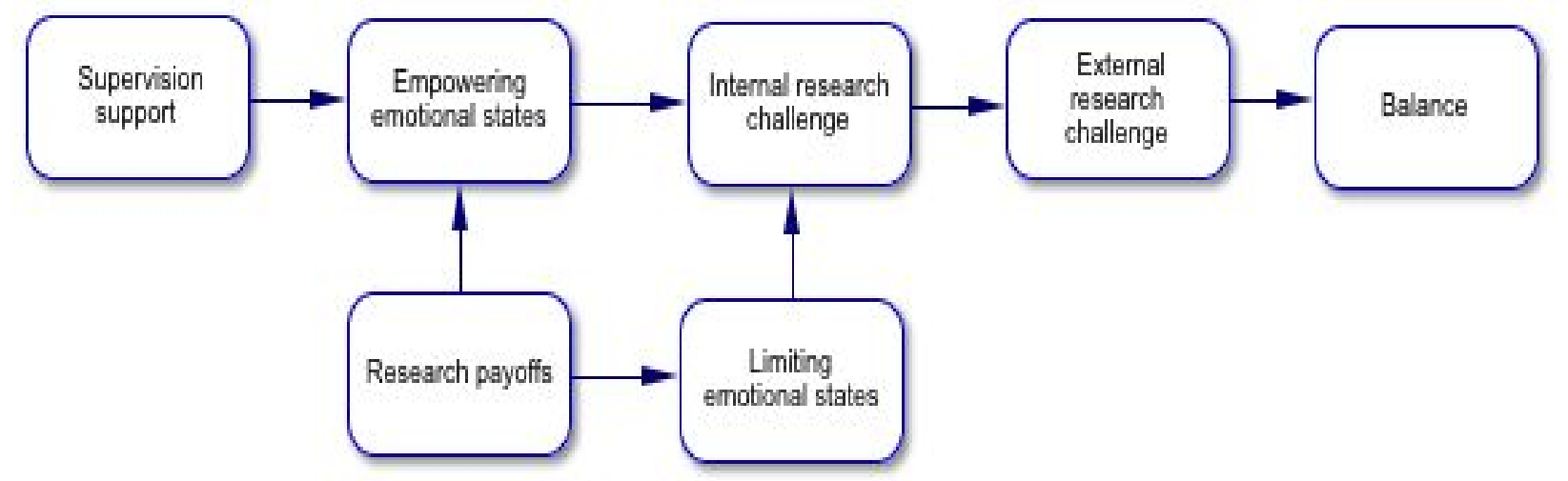

Figure 2: Systems influence diagram for supervisors 
Supervisors saw themselves and their support as a primary driver (cause) in the way students experience research. These supervisors see research payoffs influencing both the students' empowering emotional and limiting emotional states. Both of these influence their perceptions of internal research challenges (which are a pivot) that affect external research challenges. Balance is the primary outcome, which is reflected in overcoming time pressures and attaining balance and completion of the qualification.

It seems that students see supervisors as one of the elements in the way they experience research and not as a primary influence as the supervisors see themselves. This finding confirms the observations of Beqiri et al. (2010) and (Eneau 2008) that mature students take ownership of their learning. The students are managing their own research process. They see supervisors as one aspect in the chain of influence. Research education is the primary influence and personal feelings the primary effect in the relationship chain. This finding is important for supervisors to take note of as they often see themselves in the traditional power relationship with students (Manathunga 2005) whereas mature students are autonomous and manage their own learning.

The student SID confirms the importance of firstly the solid research educational base, secondly the multiple levels of support (reflected in the affinities in the central section of the SID) and finally the personal dimension (feelings as the primary outcome of the SID). This provided the foundation and rationale for the development of the framework.

\section{Multi-level researcher development framework}

The affinities generated in the focus group phased served as a guide for designing the interview guide for both students and supervisors.

\section{Research education}

Research educational input, structure, support and application are important for students. The following comment illustrates this: 'It was like stuff I learned then, only sunk in when you start to really having to work with it' (St1). This quote illustrates the liminal space noted by Raiker (2010). It is thus important to build cognitive structures so students are more aware of connections between theory and application during independent research.

The contested issue of the timing of research coursework (Kearns et al. 2008; Wagner et al. 2011) was reflected in two opposing comments by two students:

... the structure of how the research is presented in parallel with coursework does not work. ... to have all this going on and still focus on research tools ... well, that remains theoretical and then unhelpful. Research is something you do. So it is tangible. (St4) 
I was surprised that it [Research method coursework] started so early. I thought the outline was so well done, because it is in line with the practical side of your course ... From the onset you take us through ... you could make the connection from early on. ... it was practical and from the very beginning, we were sort of forced to make that link to research. ... I think there was a nice sequence, a build up from the basics. (St8)

The first comment reinforces Burke and Hutchins' (2007) assertion that for learning to be more effective, the purpose and application must be clear. The second comment emphasises the need for extended time periods for research skills to develop sufficiently (Kearns et al. 2008).

\section{Support}

As was illustrated in the SID, the students do not see the supervisor playing such a central role, but rather as forming part of the meta-process of research. These students use their own agency when seeking additional knowledge and thus seem to be more independent (Beqiri et al. 2010; Eneau 2008). Students refer to various forms of support and the following comment illustrates the value of working with fellow students:

... it served to really get me to show up, one wants to succeed and do better because the group as a whole are so positive. So I think it gets one out of a comfort zone ... it is not a competitive one, ... you want to actually give it your best, because everybody else is really putting themselves out there. (St5)

Students thus value peer support which confirms the findings of Samuel and Vithal (2011). They also referred to institutional support, such as helpful librarians.

\section{Personal feelings}

The finer nuances of changing feelings over time emerged during the interviews; and initially, at the start of the course, they reported being overwhelmed and experiencing self-doubt, fear and anxiety. Clegg et al. (2006) note that this unsettling period can be an impetus to learning. Students reported that during the coursework year their fear dissipated to an extent. However, at the start of independent research, they felt increased anxiety and loss of confidence, which is similar to the findings of Raiker (2010). When they started applying their knowledge whilst doing their research, they first seemed to lose and then regained confidence. They reflected on their emotions and noted the paradoxical value of anxiety:

I don't think that I had a full night's sleep [during fieldwork]. I was really anxious. So there is that kind of dichotomy about that I did not know it makes you anxious, and thank goodness for it, it makes you work a bit harder. (St1) 
Furthermore there was evidence of meta-reflection, pride and longer term thinking:

my feelings really went from I do not want to do this to I love this, I want to do more of this, I actually think one day I might consider a Ph.D. It was very positive in the end (St6)

This quote suggests effective researcher development noted by Evans (2011) and reflects the ontological development (Dall'Alba and Barnacle 2007) and taking ownership of the student over the course of time, while mastering the application of research skills. The personal significance of the learning in research suggests the importance of focusing more on ontological development during research training.

It seems as if 'feelings' is the proxy affinity controlling the final research output. This finding suggests that universities should focus on providing positive emotional empowerment in the complex mix of institutional, teaching and supervisory support. This focus is important for the completion of studies, due to the unique challenges facing mature, senior post graduate researchers.

\section{Supervisor perspectives}

The supervisors in this study are all professional coaches, so taking note of their strategies for supporting students may be helpful in designing a multi-level researcher development framework.

Regarding the educational process, one supervisor noted: 'I don't think this [research] is a challenge ... It is just a process ... our purpose ... is to get [the students to] an exponential understanding of research' (Su2). This comment illustrates the importance of the transferability of skills (Evans 2014) that should be a focus in teaching research. During the second year when working with supervisors, students do need to be taught the basics of research, but application is more important for knowledge consolidation. Application will help students make cognitive links (Raiker 2010) between theory and practice when conducting research activities at a later stage. One supervisor reflected on cognitive development during research and was aware of unrealistic expectations: 'You have got to gauge that. Some students definitely just require more ... they struggle more. And there are others who get it' (Su3). Supervisors are thus aware of the need to tailor-make and provide individualised support. They noted that it is important to consider student learning styles, emotional issues and their competing demands when considering support for this group.

Supervisors seem to be aware of personal engagement and investment that research 
requires but that it is not an easy process. Personal engagement is the key to ontological development of their identity (Dall'Alba and Barnacle 2007; Sinclair et al. 2014), but this development takes place over time. This identity is unique as noted by one supervisor:

There is quite an identity involved in being a researcher ... is a different identity to being a student ... they got [research] techniques, but not the identity. (Su1)

These students may not see themselves as primarily researchers but as practitioners. Therefore, it may be helpful to promote the notion of research skill development to enhance an evidencebased approach to their professional practice.

Supervisors focused on emotional states for empowerment for the research process and for successful completion. They noted that students battle with acquiring research skills and a supervisor indicated one useful strategy may be to focus students' attention on vision and identity:

I think there is a bigger focus ... why am I doing this? ... they sometimes forget that longer term purpose. (Su1)

the payoff you know, they are so proud of themselves ... a passion inside them for what they do. (Su2)

In summary, students need the research educational foundation, they need support along the way and they need to focus on their feelings in developing their identity. These three elements need to be provided by the students themselves, the supervisors and the institution. The following table (Table 1) illustrates the concepts that emerged from the findings.

Table 1: Multi-level researcher development framework

\begin{tabular}{|l|c|c|c|}
\hline & Personal characteristics & $\begin{array}{c}\text { Supervisor } \\
\text { support }\end{array}$ & $\begin{array}{c}\text { Institutional } \\
\text { context }\end{array}$ \\
\hline Feelings & $\begin{array}{c}\text { Personal engagement } \\
\text { Ownership } \\
\text { Ontology }\end{array}$ & $\begin{array}{c}\text { Vision of purpose } \\
\text { Researcher identity } \\
\text { (evidence based practice) }\end{array}$ & $\begin{array}{c}\text { Researcher development } \\
\text { Creating positive } \\
\text { empowering environment }\end{array}$ \\
\hline Support & Relational: & Promote development & Structural \\
& Family/friends & Individualised guide \\
Provide cognitive links & Administrative \\
& Peers & Technical \\
\hline Research & Mind-set & Learning styles & Scaffolded learning \\
education & Focus & Alignment \\
& Self-study & Clarity of purpose \\
& Own agency & & Application \\
\hline
\end{tabular}

There are three main factors influencing the completion of the research reflected on the horizontal level and these are the personal characteristics of the student, the supervisory support and the institutional context, which includes the research training and support. These factors, therefore, need to be considered when supporting students in completing research. On the 
vertical level, research education as the primary driver; support; and feelings (the primary outcome) reflect the students' systems influence diagram. In each horizontal band are key elements for researcher development. The centre column reflects key elements that the supervisor focuses on in their supervision of students (as identified in the supervisor interviews) and can provide guidance for supervision roles at the intersection between the student and the external environment of research (institution). This table could serve as a guide regarding how to facilitate research development related to educational input, support and feelings, which could contribute to more effective strategies of postgraduate supervision.

\section{CONCLUSIONS}

Contrasting views of research experiences identified through the IQA study provides insight into ways to support students and supervisors and ways to revise researcher development activities. Research activity in the context of this study is a complex open system experienced differently by the various constituent groups. Different groups constructed different pictures of how they experienced this complex phenomenon as reflected in the respective SIDs.

The aim of the study was to establish the various elements in the system, the relationships between the elements and to compare the various groups' perspectives of the phenomenon under study. In the case of this study, the phenomenon was the experiences of the research component of study of the students in the business school. It seems that there is a discrepancy in the ways that supervisors and students view the supervisor's role in support. It seems that students are more focused on formal educational knowledge. With this research knowledge content as a base, they manage their own knowledge in various ways; through their own agency by accessing and utilising tools and technology or through using relational, institutional and supervisory support as sustenance mechanisms.

The way students view research can provide insight to ways to support students during the course of their studies. Support needs to take place on various levels as suggested in the multilevel researcher development framework reflected in Table 1. The reported strategies used by supervisors to support students is reflected in this table. As these supervisors are professional coaches, the insights gleaned may provide other supervisors with useful insight into supporting students in their research journey. The implications for practice consist of three main themes for attention:

\section{- Research educational input:}

Increased synergy between practice and research in teaching of both research and practical content in the programme is important. Evidence-based practice examples should be utilised 
to indicate research application after obtaining a professional qualification. Research-based knowledge should be taught with a focus on application. Scaffolded learning and distribution of input to coincide with when students need the relevant knowledge, is important. It is also necessary to facilitate development of knowledge management skills so students can access their own tools and technologies for learning.

\section{- Support:}

Facilitating the use of various types of support, such as institutional, administrative technical, supervisory, peer and personal support networks, should be considered. Various types and modes of learning (face-to-face and blended learning) should be provided. Support should also adapt to various learning styles and needs of students. Supervisor support platforms may be necessary especially where supervisors are consultants and not primarily academics.

\section{- Personal engagement:}

Students need to have an individual vision of purpose, which should tie up with their professional identity. The focus should be on becoming evidence-based practitioners and life-long researchers. Efforts should be made through providing institutional support and educational input to empower students to manage their own research process and thus take ownership of their study.

Further research can focus on the learning trajectory in the process of becoming a researcher. Identification of the aspects where students have gained insights during the research process could assist institutions to focus appropriate support for students to ensure completion of research in postgraduate studies.

Being aware of the perceptions of the experiences of research of the various stakeholders provided insight into the elements each group perceived to be relevant to their context. In addition, to see how each group viewed the cause and effect (influences) of all the elements in the system afforded further insight. By contrasting and comparing the views of supervisors and students regarding the elements of research experience, the researcher development efforts could be adapted to align more closely to the needs and perceptions of each group. Changing needs of students in the knowledge economy demand alternative response for educational provision. Research leaders can no longer revert back to traditional notions of supervision but need to align contrasting experiences and expectations in deciding on researcher educational interventions. Aligned support on multiple levels in the system could contribute to more effective researcher preparation and support for timeous completion of studies and to developing life-long researchers that make a contribution to knowledge creation. 


\section{ACKNOWLEDGEMENT}

This work was supported by the Fund for Innovation in Researching Teaching and Learning (FIRTL) initiative at Stellenbosch University.

\section{REFERENCES}

Abrandt Dahlgren, M. A., H. Hult, L. O. Dahlgren, H. H. Segerstad and K. Johansson. 2006. From senior student to novice worker: Learning trajectories in political science, psychology and mechanical engineering. Studies in Higher Education 31(5): 569-586.

Alauddin, M. and A. Ashman. 2014. The changing academic environment and diversity in students' study philosophy, beliefs and attitudes in higher education. Higher Education Research and Development 33(5): 857-870.

Albertyn, R. M., C. A. Kapp and E. M. Bitzer. 2008. Profiling exiting postgraduate students' performance and experiences. South Africa Journal of Higher Education 22(4): 749-772.

Albertyn, R. M., P. Machika and C. Troskie-de Bruin. 2016. Towards responsible massification: Some pointers for supporting lecturers. African Education Review 13(3\&4): 49-64.

Albertyn, R. M., S. van Coller-Peter and J. Morrison. 2016. Aligning student and supervisor's perspectives of research challenges. In Postgraduate supervision: Future foci for the knowledge society, ed. M. Fourie-Malherbe, R. M. Albertyn, C. Aitchison and E. M. Bitzer, 171-187. Stellenbosch: Sun Media.

Ball, A. 2009. Toward a theory of generative change in culturally and linguistically complex classrooms. American Educational Research Journal 46(1): 45-72.

Barnett, R. 2000. Supercomplexity and the curriculum. Studies in Higher Education 25(3): 255-265.

Basturkmen, H., M. East and J. Bitchener. 2014. Supervisors’ on-script feedback comments on drafts of dissertations: Socialising students into the academic discourse community. Teaching in Higher Education 19(4): 432-445.

Beqiri, M. S., N. M. Chase and A. Bishka. 2010. Online course delivery: An empirical investigation of factors affecting student satisfaction. Journal of Education for Business 85(2): 95-100.

Biesta, G. 2012. Have lifelong learning and emancipation still something to say to each other? Studies in the Education of Adults 44(1): 5-20.

Boehe, D. M. 2016. Supervisory styles: A contingency framework. Studies in Higher Education 41(3): 399-414.

Blum, L. D. 2010. The 'all-but-the-dissertation' student and the psychology of the doctoral dissertation. Journal of College Student Psychotherapy 24(2): 74-85.

Brodin, E. M. 2015. Conditions for criticality in doctoral education: A creative concern. In The Palgrave Handbook of critical thinking in higher education, ed. M. Davies and R. Barnett, 265-282. New York: Palgrave MacMillan.

Boyd, B. and C. Smith. 2016. The contemporary academic: Orientation towards research work and researcher identity of higher education lecturers in the health professions. Studies in Higher Education 41(4): 678-695.

Buissink-Smith, N., S. Hart and J. van der Meer. 2013. 'There are other people out there?' Successful postgraduate peer groups and research communities at a New Zealand University. Higher Education Research and Development 32(5): 695-705.

Burke, L. A. and H. M. Hutchins. 2007. Training transfer: An integrative literature review. Human Resource Development Review 6(3): 263-296.

Carlile, P. R. 2004. Transferring, translating and transforming: An integrative framework of managing 
knowledge across boundaries. Organization Science 15(5): 555-568.

Christie, H., M. Munro and T. Fisher. 2004. Leaving university early: Exploring the difference between continuing and non-continuing students. Studies in Higher Education 29(5): 617-636.

Clegg, S., M. McManus, K. Smith and M. J. Todd. 2006. Self-development in support of innovative pedagogies: Peer support using email. International Journal for Academic Development 11(2): 91-100.

Cloete, N., J. M. Mouton and C. Sheppard. 2015. The Doctorate in South Africa: Discourse, data and policies. Cape Town: African Minds.

Croussard, B. 2013. Conceptualising doctoral researcher training through Bernstein's theoretical frameworks. International Journal for Researcher Development 4(2): 72-85.

Dall'Alba, G. and R. Barnacle. 2007. An ontological turn for higher education. Studies in Higher Education 32(6): 679-691.

Dysthe, O., A. Samara and K. Westrheim. 2006. Multi-voiced supervision of master's students: A case study of alternative supervision practices in higher education. Studies in Higher Education 31(3): 299-318.

Edwards, A. 2011. Building common knowledge at the boundaries between professional practices: Relational agency and relational expertise in systems of distributed expertise. International Journal of Educational Research 50(1): 33-39.

Eneau, J. 2008. From autonomy to reciprocity, or vice versa? French personlaism's contribution to a new perspective on self-directed learning. Adult Education Quarterly 58(3): 229-248.

Engebretson, K., K. Smith, K. McLaughlin, C. Siebold, G. Terret and E. Ryan. 2008. The changing reality of research education in Australia and implications for supervision: A review of the literature. Teaching in Higher Education 13(1): 1-15.

Evans, L. 2011. The scholarship of researcher development: Mapping the terrain and pushing back boundaries. International Journal for Researcher Development 2(2): 75-98.

Evans, L. 2014. What is effective research leadership? A research-informed perspective. Higher Education Research and Development 33(1): 46-58.

Fenge, L-A. 2012. Enhancing the doctoral journey: The role of group supervision in supporting collaborative learning and creativity. Studies in Higher Education 37(4): 401-414.

Frick, B. L., R. M. Albertyn and L. Rutgers. 2009. The Socratic approach: Adult leaning perspectives. Acta Academica Supplementum 1: 75-102.

Golde, C. M. 2005. The role of the department and discipline in doctoral student attrition: Lessons from four departments. The Journal of Higher Education 76(6): 669-700.

Hodge, S. 2014. Transformative learning as an 'inter-practice' phenomenon. Adult Education Quarterly 64(2): 165-181.

Hopwood, N. 2010. Doctoral experience and learning from a sociocultural perspective. Studies in Higher Education 35(7): 829-843.

Hornsby D. J. and R. Osman. (2014). Massification in higher education: Large classes and student learning. Higher Education 67(6): 711-719.

Kearns, H., M. Gardiner and K. Marshall. 2008. Innovation in PhD completion: The hardy will succeed (and be happy!). Higher Education Research and Development 27(1): 77-89.

Kiley, M. and G. Wisker. 2009. Threshold concepts in research education and evidence of threshold crossing. Higher Education Research and Development 28(4): 431-441.

Lee, A. and B. Green. 2009. Supervision as metaphor. Studies in Higher Education 34(6): 615-630.

Lovitts, B. E. 2005. Being a good course-taker is not enough: A theoretical perspective on the transition to independent research. Studies in Higher Education 30(2): 137-154.

Manathunga, C. 2005. The development of research supervision: 'Turning the light on a private space'. International Journal for Academic Development 10(1): 17-30. 
Meyer, J. H. F. and R. Land. 2005. Threshold concepts and troublesome knowledge: Epistemological considerations and a conceptual framework for teaching and learning. Higher Education 49(3): 373-388.

Mezirow, J. 2000. Learning as transformation. San Francisco, CA: Jossey-Bass.

Northcutt, N. and D. McCoy. 2004. Interactive qualitative analysis. Thousand Oaks, CA: Sage Publications.

Pata, K. 2009. Modeling spaces for self-directed learning at university courses. Educational Technology \& Society 12(3): 23-43.

Raiker, A. 2010. Creativity and reflection: Some theoretical perspectives arising from practice. In Teaching creativity; Creativity in teaching, ed. C. Nygaard and C. Holtham, 121-138. Faringdon, UK: Libri Press.

Reid, A. and P. Petocz. 2004. The professional entity: Researching the relationship between students' conceptions of learning and their future profession. In Improving student learning: Theory, research and scholarship, ed. C. Rust, 145-157. Oxford: Oxford Rewley Press.

Samuel, M. and R. Vithal. 2011. Emergent frameworks of research teaching and learning in a cohortbased doctoral programme. Perspectives in Education 29(3): 76-86.

Sinclair, J., R. Barnacle and D. Cuthbert. 2014. How the doctorate contributes to the formation of active researchers: What the research tells us. Studies in Higher Education 39(10): 1972-1986.

Tymon, A. and S. Batistic. 2016. Improved academic performance and enhanced employability? The potential double benefit of proactivity for business graduates. Teaching in Higher Education 21(8): 915-932.

Waghid, Y. 2015. Are doctoral studies in South African higher education being put at risk? South African Journal of Higher Education 29(5): 1-7.

Wagner, C., M. Garner and B. Kawulich. 2011. The state of the art of teaching research methods in the social sciences: Towards a pedagogical culture. Studies in Higher Education 36(1): 75-88.

Walkington, C. A. 2013. Using adaptive learning technologies to personalize instruction to student interest: The impact of relevant contexts on performance and learning outcomes. Journal of Educational Psychology 105(4): 932-945.

Wenger, E. 1998. Communities of practice: Learning, meaning and iidentity. Cambridge, UK: Cambridge University Press. 